\title{
A Functional Analysis of Theme and Thematic Progression of Private Hospital Websites
}

\author{
WAN FATIMAH SOLIHAH WAN ABDUL HALIM \\ Universiti Utara Malaysia, Malaysia \\ INTAN SAFINAZ ZAINUDIN \\ Universiti Kebangsaan Malaysia, Malaysia \\ NOR FARIZA MOHD NOR \\ Universiti Kebangsaan Malaysia, Malaysia \\ fariza@ukm.edu.my
}

\begin{abstract}
Medical tourism has been seriously affected by coronavirus disease 2019 (COVID-19) that has become a huge threat to global economy. In mitigating this issue, attention needs to be given to the online promotional message strategy to boost medical tourism. However, there is a scarcity of work on medical tourism promotional discourse from the textual function perspective despite the considerable number of studies in other types of discourse. This study, therefore, aims to examine and compare the promotional discourse message strategies in Malaysia and Thailand's private hospital websites. The analysis was based on Systemic Functional Linguistic (SFL) perspective, using Halliday \& Matthiessen's model of textual analysis (2004) and Daneš' classification of thematic patterns (1974). A total of six webpages with three webpages of one Malaysian website and one Thai website were analysed in relation to theme type and thematic progression. The findings show that texts derived from the hospital websites in Malaysia and Thailand display similarities and differences pertaining to how the texts are organised in relation to their theme types and thematic patterns. Both websites from Malaysia and Thailand combined objectivity with subjectivity in choosing their themes and thematic progression since they have a preference for unmarked themes in combination with marked theme to inform and persuade readers. However, the Prince Court Medical Centre (PCMC, Malaysia) website was direct and cohesive with its short texts and use of textual themes, while the message in Samitivej Hospital (SH, Thailand) website was more indirect, less compact, and less cohesive as the texts were rather lengthy and interspersed with interpersonal themes. The findings can be a guide for copywriters, website designers or medical tourism stakeholders to be aware of meaning-making strategies in promoting medical websites for medical tourism purpose.
\end{abstract}

Keywords: Textual Analysis; Theme and Thematic Progression; Systemic Functional Linguistics (SFL); online promotional discourse; Medical Tourism

\section{INTRODUCTION}

Medical tourism is considered as one of the rapidly developing services in the industry of tourism. According to Dalen and Alpert (2019), the number of tourists who travel to other countries for medical treatment in 2017 was estimated to be between 14 to 16 million and the worldwide number is expected to rise by $25 \%$ annually. The global medical tourism market size was valued at USD 44.8 billion in 2019, driven by a few factors such as cost effectiveness, advanced technology and better quality of care provided by health institutions (Sharma et al., 2020). However, the coronavirus disease of 2019 (COVID-19), which has spread to 200 countries and has been declared a global pandemic by the World Health Organisation (WHO), is becoming a huge threat to the global economy including the medical tourism industry. Many major medical tourism sources and destination countries are affected by COVID-19 as more than 99 countries have confirmed cases while 70 governments have banned travellers from affected regions, barring flights to certain countries and changing visa requirements (IMTJ, 2020). Such restrictions resulted in a huge impact on many leading medical tourism destinations, such as Malaysia and Thailand. 
In Malaysia, one of the leading private hospitals which has been involved in promoting medical tourism claimed that Covid-19 has caused a tremendous drop in medical tourism revenue by $66 \%$ in April and 55\% in May 2020 (Buletin Mutiara, 2020). Furthermore, the Malaysia Healthcare Travel Council or MHTC reported that they had decided to defer the Malaysia Year of Healthcare Travel 2020 (MyHT2020) campaign which was to be resumed in 2021 (MHTC, 2020). Meanwhile, medical tourism in Thailand, of which two-third of its revenue comes from non-Thai patients, claimed that foreign tourist arrivals plunged dramatically by $76 \%$ in March, with arrivals for the full year seen dropping by $42 \%$, to 15 million since the borders were mostly closed as part of the state-of-emergency order imposed in the country (Bangkok Post, 2020). The impact of the reduced medical travel to Malaysia and Thailand, which was once seen as a sector full of profit and promises, could be seen in the uncertainties that loom over the future of medical tourism.

This situation has resulted in Malaysia and Thailand taking aggressive approaches to contain the revenue drop that they have had to bear as a result of the pandemic. For example, medical tourism was the first tourism sector to be reopened in Malaysia following a variety of standard operating procedures (SOPs) as several Indonesian medical tourists were allowed to enter the country for cardiovascular and oncological treatment (MHTC, 2020). Meanwhile, Nikkei Asian Review (2020) reported that Thailand has also taken similar approach to fight the repercussion of the pandemic by allowing the first batch of Chinese medical tourists who are expected to arrive in August 2020 as Thailand has 85 private hospitals and clinics that have signed up to accept foreign tourists under various medical programmes. In fact, Thailand is a key destination for Chinese tourists who seek IVF abroad because of the more affordable services provided by the country (Nikkei Asian Review, 2020).

Despite the bold approaches taken by Malaysia and Thailand in allowing international medical tourists to visit the countries to generate revenue, the approaches cannot be materialised if there is no effective online promotion to convince the prospective medical tourists to visit the countries. Loda (2011) emphasised the role of online promotion by claiming that high-quality online information is extremely important to attract the attention of medical tourists. Realising the importance of online promotion in regaining the confidence and trust of international medical tourists in the wake of the pandemic, Malaysia has actively pursued an aggressive public relation and branding campaign, boosting social media activity, and supporting their member hospitals and agents in other countries as a means of positioning Malaysia as 'top of mind' when patients decide to travel again (MHTC, 2020). Meanwhile, it has been highlighted in Thailand Medical News (2019) that among the significant factors in boosting the revenue of the country's medical tourism industry is the increased provision of proper medical marketing professionals as it is believed that online medical marketing needs strategic planning as depending on websites alone is not enough.

Research on promotional messages has been studied and analysed in various promotional materials i.e. blogs (Viladrich \& Faust, 2014), websites (Aghbolah et al., 2021; Jun, 2015; Stoian \& Dejica, 2016), online magazines (Samynadan, 2018) and advertorials (Nurul Amilin, 2014). However, there has been very limited studies that researched on promotional message and strategy on medical tourism discourse that are specifically related to private hospital websites. Aghbolah et al. (2021) point out that the ways in which private hospitals entice medical tourists to use their medical services still remains under-researched. Private hospital websites promoting medical tourism are significant marketing channels for showcasing and promoting destinations' medical facilities and their array of staff expertise, services, treatments and equipment to both domestic and foreign patient-consumers (Mason \& Wright, 2011; Turner, 2011; Woo \& Schwartz, 2014). Nonetheless, the existing research on online medical tourism information has focused mainly on medical travel facilitators' websites (Moghavvemi, 2017), such as medical traveller planner website (Temizkan \& Konak, 2018), 
thermal tourism facilities websites (Inci \& Sancar, 2017) and official websites of National Destination Management Organisations (DMOs) (Borzyszkowski \& Lubowiecki-Vikuk, 2019). Based on the review of past literature, it was found that only a few studies have examined online promotional message strategies in private hospital websites. Therefore, as a response to the dearth of studies in the area, this study examined tourism promotional messages from a textual viewpoint, and carried out a small-scale comparison of medical tourism websites from Malaysia and Thailand.

The medical websites promote the respective private hospitals, whilst providing a guide to medical tourists towards obtaining the right information. Additionally, the websites also encourage prospective medical tourists to approach private hospitals and ultimately get the treatment for particular illnesses based on the services promoted on the websites. Taking two private hospital websites as the study's sample, the purpose of this study was twofold. First, it aimed to examine the strategies of promotional messages on the websites of two private hospitals, one from Malaysia and the other from a private hospital in Thailand; and secondly, to conduct a comparative study due to the lack of comparative studies about hospital websites that promote medical tourism. The comparative perspective comes with the premise that different countries are expected to have different promotional messages (Stoian \& Dejica, 2016), thus, justifying why hospital websites from the two countries are being investigated. In this study, the theme and thematic progression patterns are compared and contrasted to explore the diverse ways in which Malaysia and Thailand promote private hospitals for the medical tourism industry.

Promotional messages strategy can be analysed from different perspectives. The theoretical perspective chosen for this study comes from the means of Systemic Functional Linguistics (henceforth SFL). In this study, the private hospital websites were analysed and compared in relation to the way the texts were organised according to their theme types and thematic progression. The analyses employed SFL (Halliday, 1985, 1994; Halliday \& Matthiessen, 2004) and thematic patterns (Daneš, 1974) as the framework of this study. Analysis of the promotional messages of the selected websites was conducted using this model in relation to the point of view of how the selection of textual metafunction, which is the theme and thematic progression patterns, are combined to make meaning. This study also attempted to reveal how each element contributed to the promotion and messages to gain a better understanding of the combined messages in the websites. Theme choice and thematic progression patterns are important elements in the promotional text composition as theme structure forms the coherence and internal organisation of a discourse by organising the initiation of the clause and directing the attention of the receiver of the message to the parts the senders intend to emphasise (Dejica, 2009). Derewianka and Jones (2016) explained that textual resources enable a writer to organise ideas, attitudes and so on into texts that coherently hang together and relate to the context (as cited in Gebhard \& Accurso, 2020). Furthermore, failure to appropriately handle the flow of information and how the meaning of a text unfolds leads to the production of an incoherent, unintelligible text (Alrajhi, 2020).

Accordingly, a good thematic structure organisation in the promotional text would enhance the effectiveness of the promotional messages to medical tourists. For this reason, the results of this study would be able to contribute to the body of knowledge in the area as it could help reveal the way in which copywriters made clear their underlying concerns and priorities. Additionally, the findings could serve as a guideline for copywriters and medical tourism stakeholders in composing effective messages for online marketing materials, especially in promoting medical tourism through the websites of hospitals and more specifically, those of private hospitals. 


\section{LITERATURE REVIEW}

\section{PROMOTIONAL MESSAGES IN PROMOTING MEDICAL TOURISM}

In the areas of promotion and business, promotional messages play a significant role in terms of marketing or promoting services and expertise, and persuading prospective clients. Recently, investigation on promotional messages has become prevalent in the medical tourism industry and has been studied using a variety of approaches and different forms of media, including websites (Aghbolah et al., 2021; Moghavvemi et al., 2017; Jun, 2015), blogs (Viladrich \& Faust, 2014) and online magazines (Samynadan, 2018). Additionally, the investigation has mainly involved promotional strategies in delivering the messages to potential medical tourists.

Since the medical tourism market is open to international medical tourists, online promotional materials such as websites continue to grow as they present many opportunities for medical tourism players such as private hospitals and government agencies to improve efficiencies in communication engagement. Jun (2015), Viladrich and Faust (2014), Moghavvemi et al. (2017) and Samynadan (2018) reported that online promotion of medical services should be employed as the primary channel to deliver health information to medical tourists as well as a primary channel to promote medical tourism in the respective countries. Jun (2015) asserted that her study of "top-level" general hospitals with other medical tourism service providers in Korea using data from online promotional messages can serve as a guide for future researchers in conducting content analysis of medical tourism messages on the Internet. In a similar vein, Viladrich and Faust (2014) examined promotional strategies and messages in cosmetic surgery websites and blogs in Argentina. They discovered that the online promotional messages and strategies employed have successfully highlighted and promoted Argentina as a rising destination for cosmetic surgeries where Argentines are depicted as surgically enhanced role models to be imitated by other foreign medical tourism stakeholders. Meanwhile, in the local context of Malaysia, Samynadan, (2018) in her study revealed that in promoting medical tourism, online magazines can provide promotional messages which serve to attract, persuade, and allure prospective medical tourists to travel to Malaysia for medical tourism purposes. Nonetheless, Moghavvemi et al. (2017)'s study highlighted a need for private hospital managers to improve their hospitals' online presence and interactivity.

It is evident that investigation and analysis of promotional strategies have been carried out using different perspectives and approaches. A few studies employed genre analysis to examine rhetorical structure in promotional texts (Aghbolah et al., 2021; Izquierdo \& Blanco, 2020). Aghbolah et al. (2021) examined the rhetorical structure of the "About Us" sections of private hospitals websites while Izquierdo \& Blanco (2020) conducted rhetorical analysis to examine the rhetorical macrostructure in herbal tea promotional texts using move analysis method. However, the genre analysis utilised in these studies were used to examine only genres within the area of language for specific purposes (LSP). Furthermore, this approach focused on communicative functions referred to as moves and rhetorical strategies called steps.

Meanwhile, some studies employed Systemic Functional Linguistic (SFL) as SFL places the function of language as central in discourse analysis. Based on the review of past literature, studies that employed SFL approach in examining their discourse with regards to the use of theme type and thematic progression are about media texts (Lu, 2002; Potter, 2016; Drid, 2019), marketing discourse (Nurul Amilin, 2014; Alyousef, 2016), academic writing (Abdul Ridha, 2014; Emilia, 2014; Alyousef, 2015; Noori, 2015; Gunawan \& Aziza, 2017), textbooks (Jalilifar \& Montazeri, 2017; McCabe, 1999), folktales (Patpong, 2013), tourism website (Stoian \& Dejica, 2016) and medical text (Kazemi, 2015; Rodriguez-Vergara, 2017; Alrajhi, 2020) and research article (Alyousef \& Alzahrani, 2020). These studies demonstrated that while SFL-based research in examining theme and thematic progression have given 
considerable attention to discourse used in tertiary education, media genre and tourism industry, the area remains understudied in medical tourism discourse.

Studies that compared online promotional message strategies in websites of private hospitals from two different countries were particularly even more limited in number. For example, Moghavvemi et al. (2017) provided a comparative insight into how private hospital websites in India, Malaysia and Thailand present themselves in promoting medical tourism but only focusing on the content and format of private hospital. Another comparative study that involved private hospital is a study by Herwina et al. (2020) that examined whether Malaysia and Thailand are on par in terms of their service culture in medical tourism. Meanwhile, there are a few comparative studies that focused on the strengths and weaknesses of developing countries in promoting medical tourism such as motivations, challenges and opportunities of medical travel (Wong \& Ghazali, 2012; Wong et al., 2014), strategic advantages responsible for the competitiveness of medical tourism market (Ebrahim \& Ganguli, 2019) and medical tourism policies (Hafizan et al., 2018; Pocock \& Phua, 2011). It is therefore pertinent that the research gap identified in the literature is bridged. Specifically, the present study used an SFLbased approach to compare and contrast the thematic structure in medical tourism discourse found in two websites of private hospitals from Malaysia and Thailand. The present study aims to explore the similarities and differences of theme analysis and thematic progression in Malaysia's and Thailand's private hospital websites for the promotion of medical tourism industry.

\section{ANALYTICAL FRAMEWORK}

This section presents the theoretical framework used for data analysis. It discusses Systematic Functional Linguistics (SFL), theme and rheme, types of theme and thematic progression which are central to the study.

\section{SYSTEMIC FUNCTIONAL LINGUISTICS}

In linguistics, the term 'text' refers to "any passage, spoken or written, of whatever length, that does form a unified whole" (Halliday \& Hasan, 1976, p. 1). As Halliday and Hasan (1976) argued, texts are best regarded as semantic units not of form, but of meaning. Therefore, the delivery of meaningful messages in texts is of paramount importance. Systemic Functional Linguistics (SFL), founded by the works of Halliday, is a "very useful descriptive and interpretive framework for viewing language as a strategic, meaning-making resource" (Eggins, 2004, p. 2). These communicative functions include ideational which is concerned with how reality is developed in a discourse; interpersonal which is concerned with the grammatical choices that assist individuals to enact their different and complex interpersonal relations; and textual which relates to the communicative nature as well as internal structure of a text (Halliday \& Matthiessen, 2004). Textual metafunction is significant as it simplifies the organisation of the text clauses in such a way that is effective and appropriate to the context, and simultaneously, succeeds in accomplishing the desired purpose (Eggins, 1994). Of the three metafunctions, the current study relates to the textual metafunction which studies the theme and information structure of texts.

\section{THEME AND RHEME}

Halliday defines 'theme' as "the point of departure" for the message, and so it falls within what is called 'given' information (Halliday \& Matthiessen, 2004, p. 93). This means that speakers usually start their messages with information that has already been mentioned in the text, or 
that is shared or believed to be of mutual knowledge among the participants of the interaction. For example, in the sentence, 'Ziya bought a new car', the theme is Ziya. The rest of the sentence basically forms what is known as the rheme, which typically contains information that is unfamiliar or 'new'. Therefore, theme expresses the given or familiar information, that is the information that has been stated anywhere in the text or is familiar from the context. On the other hand, rheme presents new or unfamiliar information (Halliday, 1994).

\section{TYPES OF THEME}

Halliday categorises theme into three types: topical, interpersonal, and textual (Halliday \& Matthiessen, 2004). Topical themes can be categorised into two types, namely 'unmarked topical themes' as well as 'marked topical themes. Theme can be marked, which is the unusual or atypical choice such as adjuncts in declarative clauses, or unmarked, which is the usual or typical choice such as subjects in declarative clauses (Halliday \& Matthiessen, 2004). The topical theme which functions as the subject of the clause is called 'unmarked', while the topical theme which is not the subject is called 'marked topical theme' (Gerot \& Wignell, 1994; Halliday \& Matthiessen, 2004; Emilia, 2014). According to Martin et al. (1997), in a declarative clause, the unmarked topical theme can be realised by pronouns, noun phrase, grammatical item "it", existential item "there", nominal group which extends beyond the main noun, group and phrase complexes, embedded -wh clause, embedded non-finite clause, and embedded 'that' clause. In declarative clauses, marked topical themes are realised through nonsubject themes such as adverbial group or prepositional phrase.

Textual theme is the constituent which relates clause to its context (Eggins, 2004). Textual theme refers to how clauses are connected together and provide cohesion to the text. The purpose of the textual theme is to serve as the 'linking function' to highlight the unfolding or logical structure of a text in which it is particularly important in the light of the significance given to argument, insight, criticism, discussion, and analysis in the text (Emilia, 2014). The textual theme is made up of structural conjunctions, relatives and conjunctives (Martin et al., 1997). In contrast, interpersonal theme may signal the viewpoint of the writer on the message (Halliday \& Matthiessen, 2004; Thompson, 1996). Interpersonal theme deals with modal/comment, adjunct, finite/verbal operator in yes/no interrogative, mood, polarity or any combination of vocatives or personal names (Emilia, 2014). In terms of status, its choice represents the purpose of the writer and relies on whether the clause is declarative or otherwise. The element of theme can be further categorised based on its status as well as composition. Theme can be simple when conveyed by a single element which is the experiential one. However, it is possible to have more than one type of theme in a clause, which is referred to as multiple themes. However, of these three types, the topical theme is obligatory, whereas the other types are optional. Figure 2.1 presents the concept of textual metafunction based on Halliday (Halliday, 1985, 1994): 


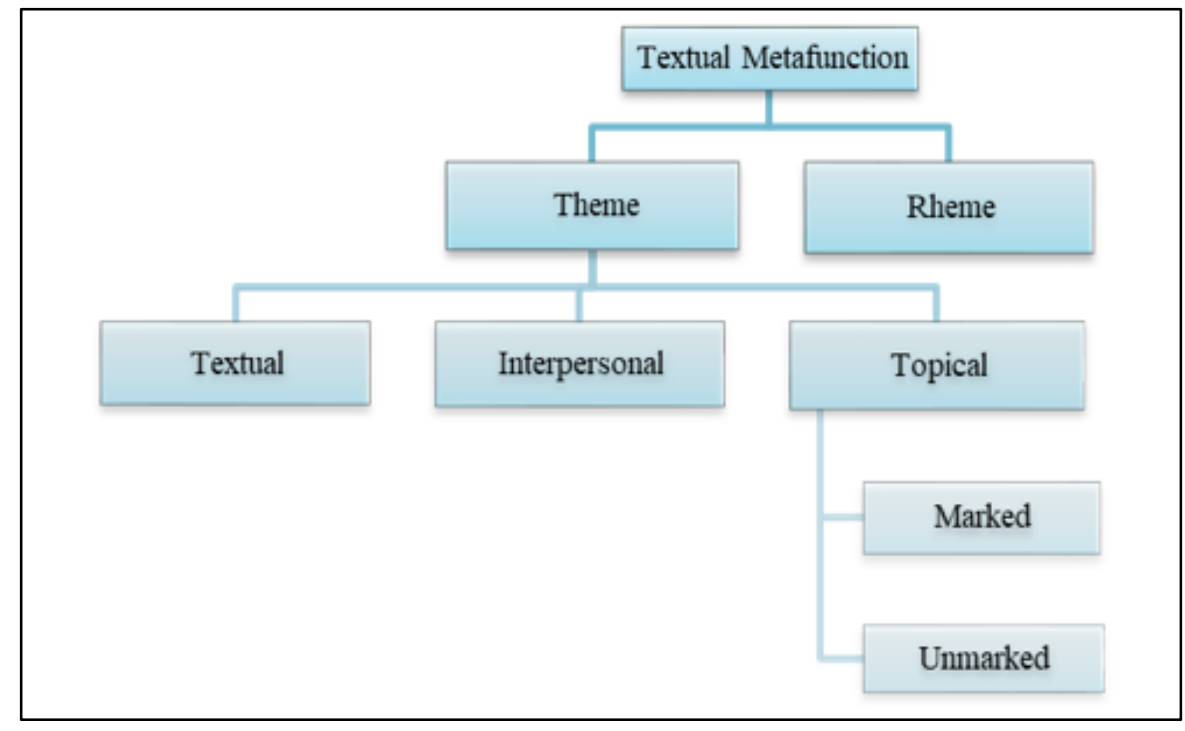

FIGURE 1. Halliday's Textual Metafunction $(1985,1994)$

THEMATIC PROGRESSION

Thematic progression was introduced by Daneš (1974) to refer to what he describes as "the skeleton of the plot" (p.114). It refers to information flow patterns in a text and the way in which information is exchanged between the pairings of the theme and rheme (Halliday \& Matthiessen, 2004). There are three main patterns for thematic progression: theme reiteration (constant theme), the zig-zag pattern (linear theme), and the multiple pattern (split rheme) (Eggins, 2004). Bloor and Bloor (2004) state that reiteration or constant theme pattern occurs when a common theme is shared by each clause. In other words, a similar theme is repeated in the themes of succeeding clauses. For example, in the sentences "Samitivej's Critical Care Complex is the result of a two-year meticulous effort by our surgeons. It offers 8 new operating rooms, 5 labor rooms". The use of "It" refers to the same theme. In the zig-zag pattern, the element that is introduced as a rheme in the first clause becomes the theme of the following clause (Eggins, 2004). An example of this pattern can be observed in the sentences "The hospital can also provide interpreters for other languages. But this will also be at the patient's additional expense". "This", which is the theme of the second clause, refers to the act of providing interpreters for other languages which is the rheme of the first clause. The third pattern is the multiple theme pattern. In this pattern, the theme of one clause introduces a number of different pieces of information in the rheme, each of which is taken up and made theme in the following clauses (Eggins, 2004). For example, in a paragraph that starts with a sentence like, "There are three reasons why PCMC is an ideal destination for medical tourism", the three elements of the rheme can be split into themes in the following clauses.

\section{METHODOLOGY}

This section presents the methodology of the study. It highlights the study design, data collection instruments and the research procedures which are all discussed in the following subsections. 


\section{DATA COLLECTION}

Web sites are the collection of web pages that make up the World Wide Web, which are the fundamental means by which information is retrieved and distributed (Germonprez \& Zigurs, 2008). Thus, this study gathered data from websites of private hospitals from two countries Malaysia and Thailand. A number of search criteria have been followed in the selection of websites. Firstly, English has been set as the language of promotion, since the study focuses on international promotion. Secondly, the focus of this study is on private hospitals from South East Asian countries that are dominant players in medical tourism market; and thirdly, private hospitals are chosen because they recorded the highest number of patients. Therefore, one website from Malaysia and one website from Thailand were chosen since the websites were obtained from the Medical Travel Quality Alliance's (2019) (henceforth MTQUA) list of the top ten hospitals in the world in 2019 for medical tourists. MTQUA listed Samitivej Hospital (henceforth SH) in Thailand in the fifth rank and Prince Court Medical Centre (henceforth PCMC) from Malaysia in the sixth rank and therefore PCMC website http://www.princecourt.com and $\mathrm{SH}$ website https://www.samitivejhospitals.com were included in the study. These websites were accessed and viewed in January 2020.

Although the websites were written by copywriters from different countries and have slight differences in format, they are comparable because they revolve around the same focus, which is promoting the expertise and facilities of the private hospitals. Since this study is a small-scale comparison study and focused on the function of each words utilised in the promotional texts in terms of how they make meaning in relation to theme and thematic progression, only selected sections of three webpages were chosen for each hospital website to be analysed. These webpages were chosen based on their function as the closest to promoting medical tourism and they address prospective international medical tourists. The webpages were also chosen based on their content which best describes the facilities and expertise of the private hospitals. The three webpages chosen from the PCMC website are the International Business Lounge (IBL), About PCMC (PCMC) and Medical Tourism (MT) while for SH, the webpages are Samitivej's New Critical Care Complex (SAM), Language \& Interpreters (L\&I) and Promoting Total Wellness (PTW). The selected sections of the six webpages are included in the Appendix.

\section{DATA ANALYSIS}

In terms of the methodology, this study adopted the Systemic Functional Linguistics (SFL) approach, focusing on textual metafunction based on Halliday \& Matthiessen's (2004) model to analyse theme and rheme, and Daneš' (1974)'s categorisation of thematic progression patterns. The analysis was done manually. SFL is a suitable tool to be applied to the current study because analysing the theme and rheme as well as inspecting thematic progression would show how copywriters organise and compose the promotional text of medical tourism discourse. This comparative analysis is important to provide different linguistic styles adopted by the copywriters of the two hospitals. Table 1 explains the analytical tools utilised throughout the study to analyse the theme types and thematic progression pattern. Further explanation on these themes and rheme elements is available in the Analytical Framework section (see page 78). 
TABLE 1. Analytical tools based on Halliday \& Matthiesen's (2004) and Daneš' (1974) model

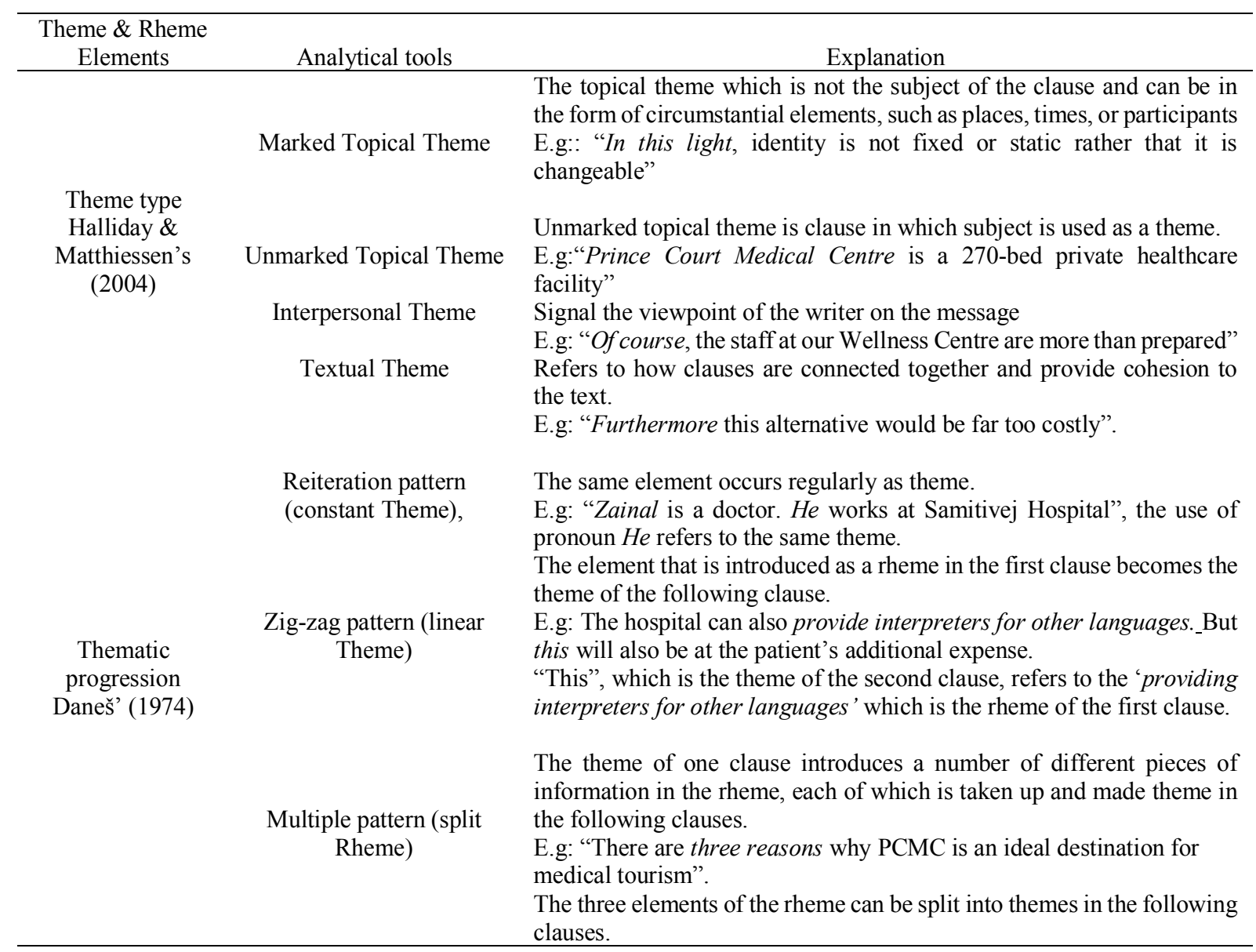

The analysis of the theme and thematic progression pattern went through several steps. Firstly, once the six webpages from the two websites were selected, the texts were divided into clauses. This was followed by the identification of the theme and rheme for each clause based on Halliday \& Matthiessen (2004)'s model, by illustrating the themes and rhemes in tables that included the three types of theme: topical, textual, and interpersonal. Secondly, for the investigation of thematic progression, the texts of the webpages were analysed in the form of paragraph. This is to facilitate the analysis of thematic progression to determine its patterns. Thematic progression patterns were analysed based on Daneš' classification of thematic patterns (1974) as explained in Thematic Progression in Analytical Framework section. Thirdly, statistical information in relation to theme types and thematic progression pattern frequencies were calculated. Finally, the findings based on the types of themes and thematic progression were displayed in tables. The flow of the data analysis process is illustrated in the Figure 2. 


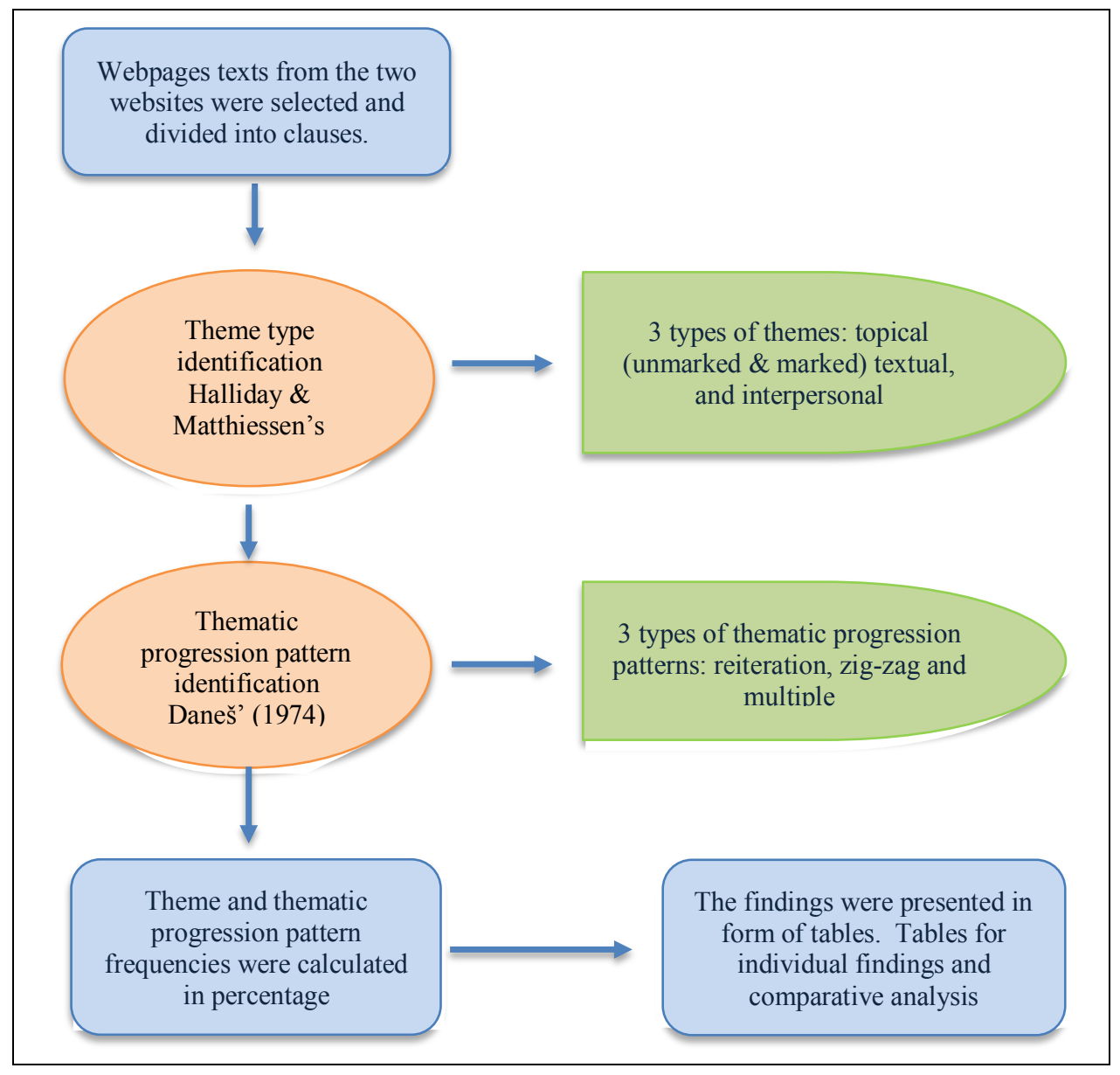

FIGURE 2. The Data Analysis Process

The tables for each hospital's findings (see Table 2 and Table 4) and table for comparative perspective (see Table 5) are included in the Findings and Discussion section to facilitate comparison between the occurrence of different patterns of theme and thematic progression in each selected webpage. In order to make the study reliable, and to avoid the effect of any differences in length, the use of percentages based on calculations of occurrences was employed to reflect the extent to which the two sets of texts are similar or different in relation to the placement of various textual elements. The percentage was calculated to identify the occurrence of each element; theme status and their thematic progression from the total of independent conjoinable clause complexes in both websites. The textual analysis examined only independent conjoinable clause complexes as this seems to be the optimal method for showing thematic progression (McCabe, 1999). The presentation of the findings in Table 2 and Table 4 included the total frequency (F) of the type of theme and thematic progression while the examples of thematic progression pattern illustrated in Figure 3,4,5,6 and 7 included the number of the clauses taken from the website text such as Clause 4 (CL4). 


\section{FINDINGS AND DISCUSSION}

The results of the theme-rheme analysis are presented based on how the textual functions are represented for each text. In the following section, the results for the text in each website are first presented and subsequently, compared in terms of their similarities and differences.

\section{PRINCE COURT MEDICAL CENTRE (PCMC) - MALAYSIA THEME TYPE}

The textual analysis of the text from PCMC website is presented in Table 2, which illustrated percentages based on the number of clauses in the three webpages taken from the PCMC website, namely International Business Lounge (IBL), About PCMC (PCMC) and Medical Tourism (MT). This section presents results for the theme type followed by thematic progression.

TABLE 2. Theme Types and Thematic Progression in PCMC Website

\begin{tabular}{|c|c|c|c|c|c|c|c|c|}
\hline \multirow{2}{*}{$\begin{array}{l}\text { Theme Rheme } \\
\text { Elements }\end{array}$} & \multicolumn{2}{|c|}{ IBL } & \multicolumn{2}{|c|}{ PCMC } & \multicolumn{2}{|c|}{ MT } & \multicolumn{2}{|c|}{ TOTAL } \\
\hline & $\mathbf{F}$ & $\%$ & $\mathbf{F}$ & $\%$ & $\mathbf{F}$ & $\%$ & $\mathbf{F}$ & $\%$ \\
\hline \multicolumn{9}{|l|}{$\begin{array}{l}\text { Theme Type } \\
\text { Topical }\end{array}$} \\
\hline + Unmarked & 5 & $22.7 \%$ & 2 & $9 \%$ & 8 & $36.3 \%$ & $15 / 22$ & $68 \%$ \\
\hline + Marked & - & - & - & - & 1 & $4.5 \%$ & $1 / 22$ & $4.5 \%$ \\
\hline Interpersonal & - & - & - & - & - & - & - & - \\
\hline Textual & 3 & $13.6 \%$ & - & - & 6 & $27.2 \%$ & $9 / 22$ & $\begin{array}{c}40.9 \\
\%\end{array}$ \\
\hline \multicolumn{9}{|l|}{ Thematic } \\
\hline Reiteration & 2 & $9 \%$ & 6 & $27 \%$ & 2 & $9 \%$ & $10 / 22$ & $45.4 \%$ \\
\hline Zig-zag & 3 & $9 \%$ & - & - & - & - & $2 / 22$ & $9 \%$ \\
\hline Multiple & - & - & - & - & 3 & $13.6 \%$ & $3 / 22$ & $13.6 \%$ \\
\hline
\end{tabular}

PCMC texts and its clauses were short and composed of declarative clauses. The textual analysis presented in Table 2 shows that the highest number of occurrence for theme type is the unmarked topical theme at $68 \%$. Next, it is followed by the textual theme at $40.9 \%$. There is no marked topical theme as well as interpersonal theme. The findings on theme types in PCMC webpages, together with its examples from the texts are presented in Table 3 below. The words or phrases in the theme position are italicised.

TABLE 3. Theme Types in PCMC Website

\begin{tabular}{|c|c|}
\hline Theme Type in PCMC Website & Types \\
\hline Unmarked topical theme & $\begin{array}{l}\text { i. Proper nouns, e.g: "Prince Court Medical Centre is a } 270 \text {-bed } \\
\text { private healthcare facility". } \\
\text { ii.Pronoun, e.g: "Our International Business Lounge is geared to } \\
\text { welcome you". } \\
\text { iii.Grammatical item 'it', e.g: "It is one of the few countries in } \\
\text { the region" } \\
\text { iv.Embedded non-finite, e.g: "Travelling to a new country for a } \\
\text { holiday can be a stressful and anxious experience for some". }\end{array}$ \\
\hline Marked topical theme & $\begin{array}{l}\text { i.Adverbial group, e.g: "Today, the medical care in Malaysia is } \\
\text { on par with the best in the world". } \\
\text { i.Structural conjunctions, e.g., "PCMC promote and develop the } \\
\text { country's medical tourism industry as well as position Malaysia } \\
\text { as a healthcare hub in the Southeast Asian". } \\
\text { ii.Relatives, }\end{array}$ \\
\hline
\end{tabular}




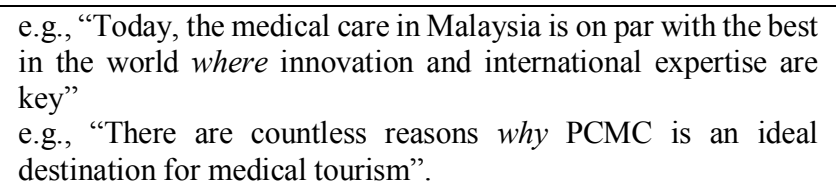

The high occurrence of unmarked topical theme position indicates that this is probably the most common method of introducing and describing information regarding the private hospital to prospective medical tourists. The hospitals seem to be drawing users' attention to the facilities and expertise offered by the private hospital. Hence, the use of unmarked topical theme in the website has the key purpose of informing medical tourists. The use of marked topical theme in PCMC webpage texts, although in limited number, helps the website designers or copywriters to foreground points that they consider important to be put in the initial position of the clause, such as manner, time, or place. Meanwhile, textual themes in PCMC webpages are realised in several ways. These textual themes are used in PCMC webpage texts to relate the private hospital clause to its context which refers to the current medical tourism market. In these examples, the clauses are connected together and provide cohesion to the text. In particular, the textual theme is important in structuring the texts because the theme operates at sentence or clause complex level (Gerot \& Wignell, 1994).

\section{THEMATIC PROGRESSION}

Concerning thematic progression pattern, the analysis shows that theme reiteration patterns $(22.7 \%)$ dominate the occurrence of the three thematic progression patterns, followed by multiple pattern $(23.3 \%)$ and zig-zag pattern $(9 \%)$. Examples of the reiteration theme pattern found in the PCMC webpage texts are presented in Figure 3.

\begin{tabular}{|lll|}
\hline CL3 & $\begin{array}{l}\text { Theme } \\
\text { Prince Court Medical Centre }\end{array}$ & is a 270-bed private healthcare facility located in... \\
CL4 & Our aim & is to be the leading healthcare provider in Asia, \\
\hline CL9 & $\begin{array}{l}\text { Malaysian healthcare } \\
\text { CL10 }\end{array}$ & offers specialties in various medical disciplines... \\
& $\begin{array}{l}\text { Today, the medical care } \\
\text { in Malaysia }\end{array}$ & is on par with the best in the world.. \\
\hline
\end{tabular}

FIGURE 3. Reiteration of theme pattern in PCMC webpage text

Figure 2 demonstrates that the theme PCMC (CL3) is reiterated in the succeeding clauses through the use of possessive pronoun 'our aim'. Similarly, the theme in CL9, Malaysian healthcare, is repeated in CL10. According to Bloor and Bloor (2004), this type of thematic progression is usually employed to focus on a specific element which refers to the private hospital and Malaysian healthcare. By repeating the theme in subsequent clauses, the prospective medical tourists are able to follow the development of the text. Theme reiteration patterns were employed in the text in order to emphasise the information. It is in line with Eggins' (2004) statement that the theme reiteration patterns are used to emphasise the focus of the topic. Thus, it can be concluded that the PCMC website copywriters achieve cohesion through repetition of a similar theme in ensuing clauses to facilitate the prospective medical tourists to understand the flow of information presented in the webpages. 
According to Bloor and Bloor (2004), the multiple theme (split rheme) pattern takes place when the rheme of a clause possesses two elements. Each of these elements are then taken up as themes of two different succeeding clauses. Examples of the multiple theme pattern found in the PCMC webpage texts are presented in Figure 4.

\begin{tabular}{|c|c|c|}
\hline & Theme & Rheme \\
\hline CL12 & There & $\begin{array}{l}\text { re countless reasons why PCMC is an ideal destination for medical } \\
\text { ourism }\end{array}$ \\
\hline CL13 & $\begin{array}{l}\text { Unique to the } \\
\text { medical tourism } \\
\text { sector in Malaysia }\end{array}$ & $\begin{array}{l}\text { is that it is one of the few countries in the region where it is promoted by the } \\
\text { government. }\end{array}$ \\
\hline CL14 & Malaysian healthcare & offers specialties in various medical disciplines and conducts some of the \\
\hline
\end{tabular}

FIGURE 4. Multiple theme pattern in PCMC webpage texts

As illustrated in Figure 3, the rheme of clause 12 (CL12) possesses two elements: the uniqueness of Malaysian medical tourism and Malaysian healthcare system. These elements are then made into different themes in the succeeding clauses. Through the introduction of multiple elements in the rheme which are then promoted as themes in the subsequent clauses, a cohesive text is produced. The zig-zag thematic pattern occurs when an element in the rheme of a clause is made as the theme in the succeeding clause (Bloor \& Bloor, 2004). The zig-zag theme pattern, though not widely used in PCMC webpages, provides cohesion by building on the rheme. An example of the zig-zag theme pattern found in the PCMC webpage texts is presented in Figure 5.

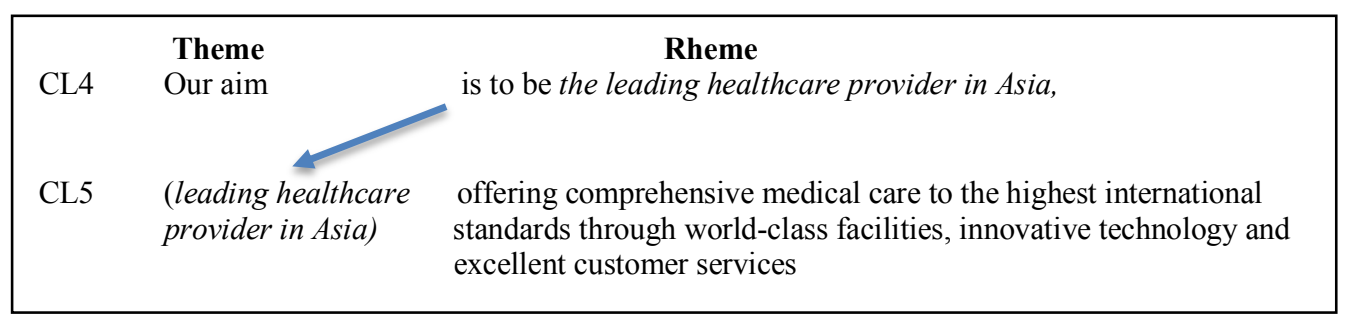

FIGURE 5. Zig-zag theme pattern in PCMC webpage texts

According to the example of zig-zag pattern in Figure 5, clause 4 (CL4) introduces the element 'leading healthcare provider in Asia'. This element is then promoted to the theme position in clause 5 (CL5). Hence, PCMC webpages employed the zig-zag thematic pattern to produce a cohesive text. It also provides readers with a text development which is cumulative (Eggins, 1994).

The total of thematic progression pattern in PCMC webpages is only $68 \%$ from the total of independent conjoinable clause units. This shows that the promotional message follows some clear pattern and do not stop at certain sentences due to the frequent use of new themes, as indicated in Table 2. This particular writing strategy draw users' attention to that particular item in the theme position, such as "Prince Court Medical Center" and "Our International Business Lounge". The presence of thematic progression indicates a clear and organised message, focusing on the promotional message conveyed by the website copywriters and private hospital management, such as the facilities offered by PCMC and the role of PCMC as an ideal destination for medical tourism. 


\section{SAMITIVEJ HOSPITAL (SH) - THAILAND \\ THEME TYPE}

In Table 4, the textual analysis of the text from the SH website shows the percentages based on the number of clauses in the three webpages of SH website, namely Samitivej's New Critical Care Complex (SAM), Language \& Interpreters (L\&I), and Promoting Total Wellness (PTW).

TABLE 4. Theme Types, Theme Composition and Thematic Progression in SH Website

\begin{tabular}{l|cccccccc}
\hline Theme Rheme & \multicolumn{2}{c}{ SAM } & \multicolumn{2}{c}{ L\&I } & \multicolumn{2}{c}{ PTW } & \multicolumn{2}{c}{ TOTAL } \\
\cline { 2 - 9 } Elements & F & $\mathbf{\%}$ & F & \% & F & \% & F & \% \\
\hline $\begin{array}{l}\text { Theme Type } \\
\text { Topical }\end{array}$ & & & & & & & & \\
+ Unmarked & 5 & $17 \%$ & 10 & $33 \%$ & 11 & $37 \%$ & $26 / 30$ & $87 \%$ \\
+ Marked & - & - & 1 & $3 \%$ & 3 & $10 \%$ & $4 / 30$ & $13.3 \%$ \\
Interpersonal & - & - & 1 & $3 \%$ & 2 & $7 \%$ & $3 / 30$ & $10 \%$ \\
Textual & 1 & $3 \%$ & 2 & $7 \%$ & 3 & $10 \%$ & $6 / 30$ & $20 \%$ \\
\hline Thematic & & & & & & & & \\
Progression & & & & & & & & \\
Reiteration & 4 & $13.3 \%$ & 7 & $23 \%$ & 6 & $20 \%$ & $17 / 30$ & $56.6 \%$ \\
$\begin{array}{l}\text { Zig-zag } \\
\text { Multiple }\end{array}$ & - & - & 2 & $7 \%$ & 8 & $26.6 \%$ & $10 / 30$ & $33 \%$ \\
\hline
\end{tabular}

The analysis revealed that the SH webpage texts were rather long and consisted of declarative and imperative clauses. The themes found in the text were mainly unmarked topical theme at $87 \%$. Interestingly, the occurrence of marked themes is rather high $(13.3 \%)$ in these selected SH webpages. Meanwhile, the occurrence of textual themes was ranked second $(20 \%)$ and interpersonal theme was ranked third (10\%) among the theme types in the selected texts. The findings of the theme types in $\mathrm{SH}$ webpages, together with the examples from the texts are presented in Table 5 below. The words or phrases in the theme position are italicised.

TABLE 5. Theme Types in SH Website

\begin{tabular}{|c|c|}
\hline Theme Type in SH Website & Types \\
\hline Unmarked topical theme & $\begin{array}{l}\text { i. Proper nouns, e.g: "Samitivej's Critical Care Complex is the } \\
\text { result of a two-year meticulous effort by our surgeons and } \\
\text { medical staff" } \\
\text { ii.Pronoun, e.g: "our eight new state-of-the-art surgical suites } \\
\text { are all fully equipped with the latest surgical technology". } \\
\text { iii.Grammatical item 'it', e.g: "It offers } 8 \text { new operating rooms". }\end{array}$ \\
\hline Marked topical theme & $\begin{array}{l}\text { i.Prepositional phrase, } \\
\text { e.g: "To this end, we have a staff of in-hospital interpreters } \\
\text { fluent in many languages" } \\
\text { e.g: "On our site, you'll find practical information about how to } \\
\text { upgrade your nutrition". }\end{array}$ \\
\hline Interpersonal theme & $\begin{array}{l}\text { ii.Adjuncts (Adverb), } \\
\text { e.g., "please do not hesitate to contact us at } \\
\text { info@samitivej.co.th" } \\
\text { e.g., "of course, the staff at our Wellness Centre are more than } \\
\text { prepared". }\end{array}$ \\
\hline Textual theme & $\begin{array}{l}\text { i.Structural conjunctions, e.g., "Not only does the Complex } \\
\text { provide the best working environment for surgeons, but our } \\
\text { eight new state-of-the-art surgical suites are fully equipped with } \\
\text { the latest surgical technology" } \\
\text { ii.Conjunctives, e.g., "We will gladly arrange an interpreter } \\
\text { outside of normal business hours, however this will be at an } \\
\text { additional expense to the patient". }\end{array}$ \\
\hline
\end{tabular}


The use of unmarked topical themes in SH webpages aims to draw users' attention to the facilities at the private hospital. Meanwhile, marked topical themes are used because it stands out. It attracts attention because it is not what one normally expects to find (Gerot \& Wignell, 1994). Thus, the choice of themes is meaningful. These examples of marked topical themes in $\mathrm{SH}$ webpages provide a contextual frame which emphasises the promotion of hospital facilities and services. Marked themes are used by the writer to draw addressees' attention to the particular group or phrase and to build a coherent text (Butt et al., 2000). Furthermore, the presence of marked themes in the text is a form of presenting a new topic or new beginning in the text as well as to scaffold the discontinuity in the text (Martin, 1992). In SH webpage texts, the use of interpersonal themes in the text aims at presenting the writer's perspective in the text while the textual themes are used in SH webpage texts to relate to the private hospital clause to its context, which refers to the conditions of services offered by the private hospital. Furthermore, the clauses are connected and provide cohesion to the text.

\section{THEMATIC PROGRESSION}

Table 4 above reveals that the most common thematic progression found in $\mathrm{SH}$ webpages is the reiteration pattern at $56.6 \%$. This is ensued by the zig-zag thematic pattern at $33 \%$. The multiple thematic progression pattern was not applied in the SH webpages. Examples of the reiteration theme pattern found in the SH webpage texts are presented in Figure 6.

\begin{tabular}{|ccc|}
\hline \multicolumn{2}{c}{ Theme } & Rheme \\
CL2 & Samitivej's Critical Care Complex & is the result of a two-year meticulous effort by our surgeons... \\
CL3 & It & offers 8 new operating rooms, 5 labor rooms... \\
& & \\
CL4 & Not only does the Complex & provide the best working environment for surgeons, \\
\hline
\end{tabular}

FIGURE 6. Reiteration of theme pattern in SH webpage texts

The texts in Figure 6 above begins with the theme Samitivej Critical Care Hospital in Clause 2 (CL2). This theme is reiterated in the succeeding clauses (CL3 and CL4) through the use of the personal 'it'. According to Bloor and Bloor (2004), this type of thematic progression is usually employed to focus on a specific element. In this case, the element is the Samitivej Critical Care Hospital. By repeating the theme in subsequent clauses, the readers are able to follow the development of the text. This repetition of the same theme contributes to a cohesive text. Meanwhile, the zig-zag thematic pattern, which was ranked second at 33\% in SH webpage texts, was employed to cumulatively explain the message. The examples of the zig-zag theme pattern found in the SH webpage texts are presented in Figure 7.

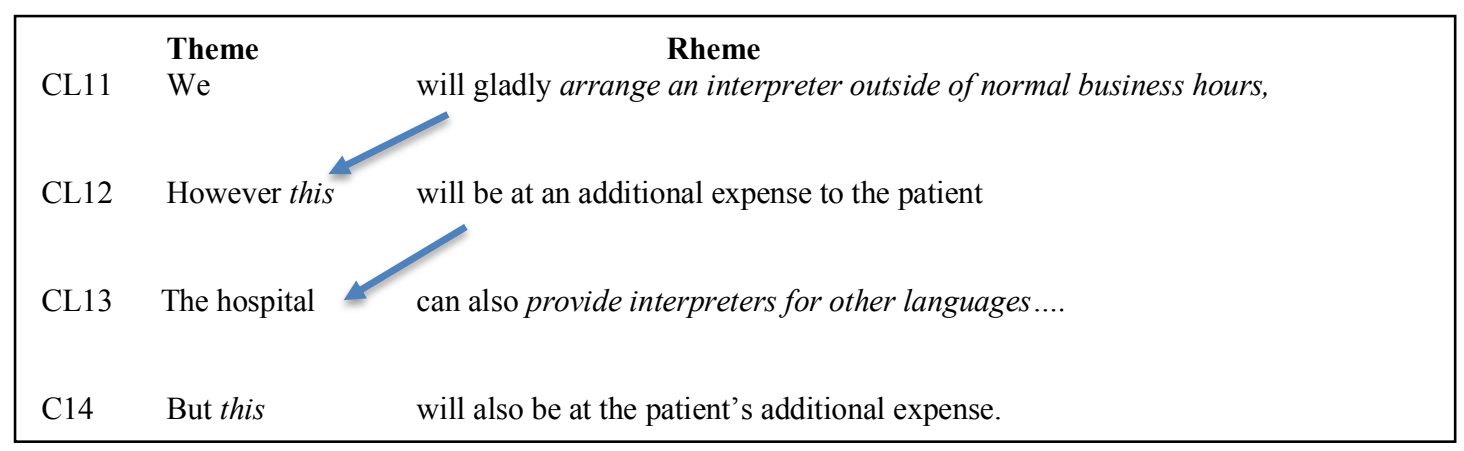

FIGURE 7. Zig-zag theme pattern in SH webpage texts 
In Figure 7, the first element, 'arrange an interpreter outside of normal business hour' in Clause 11, is promoted as the theme of Clause 12 through the use of demonstrative pronoun 'this' and The total of thematic progression pattern in SH webpages is $90 \%$ from the total of independent conjoinable clause units. As indicated in Table 4, the promotional message unfolds some established patterns as the clauses do not stop at certain sentences due to the frequent use of new themes. This writing strategy plays a significant role to link clauses in order to guide reader's comprehension towards the message. This is important as readers' comprehension of the message will lead to a positive outcome for the hospital such as a high enrolment of medical tourists.

\section{COMPARISON OF RESULTS BETWEEN PCMC AND SH WEBSITES}

Table 5 below presents findings that show the similarities and differences between PCMC and SH hospital websites (see table 5).

TABLE 5. Similarities and Differences of Thematic Structure and Progression in PCMC and SH Websites

\begin{tabular}{|c|c|}
\hline $\begin{array}{l}\text { Theme and Thematic Progression in PCMC Website } \\
\text { (Malaysia) }\end{array}$ & $\begin{array}{l}\text { Theme and Thematic Progression in } \\
\text { SH Website (Thailand) }\end{array}$ \\
\hline $\begin{array}{l}\text { Similarities } \\
\text { + All declarative clauses } \\
\text { + Dominated by unmarked topical themes } \\
\text { + Textual themes } \\
\text { + Dominated by reiteration theme progression } \\
\text { + Zig-zag theme progression }\end{array}$ & $\begin{array}{l}\text { Similarities } \\
\text { + Declarative \& Imperative clauses } \\
\text { + Dominated by unmarked topical themes } \\
\text { + Textual themes } \\
\text { + Dominated by reiteration theme progression } \\
\text { + Zig-zag theme progression }\end{array}$ \\
\hline $\begin{array}{l}\text { Differences } \\
\text { + Very few marked themes } \\
\text { - No interpersonal theme } \\
\text { + Rather high Textual themes } \\
\text { + Multiple theme progression } \\
\text { + Presence of thematic progression present }\end{array}$ & $\begin{array}{l}\text { Differences } \\
\text { + Rather high marked theme } \\
\text { + Interpersonal theme } \\
\text { + mediocre Textual themes } \\
\text { - No multiple theme progression } \\
\text { + Presence of thematic progression }\end{array}$ \\
\hline
\end{tabular}

The unmarked topical themes employed by SH webpages appear to be more convincing in persuading prospective medical tourists with frequent use of the first plural pronoun 'we' in the theme position, for example "we provide a wealth of information about easy to implement steps to improve your overall wellness" and "we want to show you how". This finding supports Alyousef's (2016) argument that the use of 'we' helps to establish rapport with readers. However, Yeung (2007) claimed differently and argued that the use of first-person pronouns cannot be considered a defining feature of business texts. Additionally, the results revealed that SH did not only employ the first person pronoun but also the second-person pronoun ' $y o u$ ' in the theme position, for example, "If you have concerns or questions about interpreters..". In these instances, audiences were directly addressed to involve their attention. According to Cui and Zhao (2013), the process of being involved deepens audiences' impression and makes them remember the message better. The PCMC webpages, on the other hand, employed the repetition of the name of the hospital and preferred the full name of a subject in the theme position.

Apart from unmarked themes, marked themes are also seen as very important to the success of the text as they guide readers and function as "contextual frame" that is staged in the progression of the written text (Emilia, 2005). In terms of online promotional materials, it would be natural for a website that has the foundation of an advertisement to naturally start with a line that may draw the attention of the readers, and consequently use marked theme in the first sentence. However, the results showed that this technique was barely employed in the PCMC webpages with only $4.5 \%$ of the text but the occurrence of marked themes in $\mathrm{SH}$ 
webpages is higher compared to PCMC with a difference of $8.8 \%$. Since the use of marked themes can also avoid the monotonous use of subject in the text and highlight particular points of circumstances (Butt et al., 2000), it is deduced that the primary purpose of the SH webpages is aimed at persuading readers, while the PCMC webpages function to inform readers. This finding corresponds with Nurul Amalin's study (2014) where the marked themes were applied to emphasise and indirectly persuade readers to contact and enrol in certain organisations. In addition, the marked themes were also adopted throughout the texts in Nurul Amalin's study, possibly to offer variety in structure to the readers so as not to appear dull. As Eggins (2007: 320) argued, "skillful writers and speakers choose marked theme to add coherence and emphasis to their text" through the use of theme predication which includes thematic and informational choices.

Meanwhile, the use of more marked themes indicates the writer's ability to produce more dynamic text which is a typicality of an academic text (Wang, 2007). A very limited occurrence of marked themes in the promotional texts of these two private hospital websites was found. PCMC and SH websites were composed of mainly declarative clauses that function as statements. Nwogu and Bloor (1991), however, contend that marked topical themes would be very beneficial in argumentative texts as they give an impact on the development of information in argumentation where arguments are arranged in a meaningful way to achieve its purpose.

Another difference in theme type is in the absence of interpersonal theme in PCMC webpages. Albeit limited in number, interpersonal theme existed in $\mathrm{SH}$ webpages. The use of interpersonal themes in the text aims at presenting the author's perspective in the text. The use of interpersonal themes scored the lowest percentage among the other types of themes in both texts because of the nature of the promotional text (Alrajhi, 2020) that could be attributed to the objectivity and impersonal traits that scientific texts are known for (Halliday \& Webster, 2004). Besides, this confirms Butt et al.'s (2000) statement who argue that interpersonal themes are more often found in spoken texts since speakers sustain their interaction. The absence of interpersonal themes in PCMC promotional texts is because the texts aim to appear objective so as not to overwhelm readers with personal opinions. Meanwhile, interpersonal themes are employed in SH texts using mood adjunct 'of course', to indicate the writer's open persuasiveness. Moreover, mental process or mood adjunct 'of course' emphasises the writer's personal voice to indicate a subjective opinion in convincing the prospective medical tourists, which is considered to be appropriate (Knapp \& Watkins, 2005).

Textual themes were employed in both webpages to provide a cohesive link to the previous messages and pay attention to the flow of the message apart from the focalisation of information. However, textual themes were widely applied in the PCMC webpages compared to SH webpages. The use of textual themes is crucial to guide prospective medical tourists' comprehension towards the message and to indicate a more compact, cohesive and connected message. Additionally, such persuasive understanding will lead to a positive outcome for the private hospital, such as higher enrolment of potential patients among medical tourists.

In terms of thematic progression, both the PCMC and SH webpages shared similarities as the reiteration theme pattern was extensively used where cohesion was achieved through repetition of an identical theme in the following clauses. This facilitates readers' comprehension in following the flow of information presented on the website. The zig-zag theme pattern was employed in both webpages to provide cohesion by building on the rheme, thus producing a cumulative progression of the websites. Where the thematic progression is concerned, there was an absence of multiple theme progression in the $\mathrm{SH}$ texts. This, nevertheless, was available in the PCMC texts, albeit in limited number. Multiple theme pattern is one of the characteristic features that is used in marketing texts to persuade readers in accepting the viability of the marketing plans (Alyousef, 2016). Alyousef (2016) also argued 
that promotional texts adopt multiple theme pattern techniques to attract audience to their marketing plans. The findings of thematic progression pattern in this study corresponds to the findings in Alyousef's (2016) study which revealed the extensive use of reiteration thematic progression pattern, followed by the zig-zag thematic progression pattern.

The flow of the message in PCMC and SH webpages was ancillary to draw prospective medical tourists' attention to the promotional message itself. The findings have shown that the thematic progression patterns from both webpages were established with the combination of a few clear patterns. This is characterised by the interconnectedness of ideas in the texts. The presentation of ideas in major portions of the texts is coherent. However, the cohesion of the texts may be disrupted with the inclusion of many new themes (Stoian, 2015). In the present study, the number of new themes in both webpages were low. Therefore, the webpages are identified as having organised thematic progression patterns. As a result, the promotional message would still be comprehensible and capable of capturing the attention of potential medical tourists.

\section{CONCLUSION}

This study focuses on the theme-rheme analysis between two private hospitals websites from two countries, Malaysia and Thailand. The findings show that both websites have their own strengths and weaknesses in terms of the way the texts are organised in relation to their theme types and thematic progression in conveying promotional messages to medical tourists. Based on the types of themes identified, both sets combined objectivity with subjectivity in choosing their themes and thematic progression since they have the preference for unmarked themes in combination with marked themes in presenting the respective hospital's website. Promotional message in Prince Court Medical Centre texts is more objective and impersonal with the absence of interpersonal themes whereas Samitivej Hospital texts appeared to be more subjective with the use of interpersonal themes. Apart from that, both websites have informative and persuasive elements. For PCMC, this was implemented through the limited use of marked themes while for $\mathrm{SH}$, this was accomplished through the frequent use of marked themes and pronouns in theme position.

The message from PCMC was direct and cohesive with the use of short texts and a high number of textual theme while the message in the SH website was more indirect, less compact, and less cohesive as the texts were rather lengthy and were interspersed with interpersonal themes and a low number of textual themes compared to PCMC texts. Results from the thematic progression revealed that the flow of message in both websites was primary to drawing prospective medical tourists' attention as the attention was both in the message flow and in the promotional message itself. Since the thematic progression was established with a few combination of thematic patterns, they were therefore identified as organised in a clear thematic pattern.

In brief, it was observed that the findings of this study show some commonality with other studies regarding the use of cohesion system in which unmarked topical theme and theme reiteration is dominant for the purpose of producing a sense of cohesiveness in the text. Although Stoian and Dejica (2016) and Alrajhi (2020) reported that there is lack of thematic progression in their studies, the findings in the present study differ. A clear thematic progression existed that demonstrated the presence of interconnectedness of ideas in the texts.

This study contributes to our understanding of theme types and thematic progression. The findings suggest that thematic organisation play an important role in the composition of a message as a whole in online promotional materials, and in this instance, in promoting medical tourism. Appropriate theme choices and thematic progression patterns play a significant role 
as both are used as effective promotional strategies to increase our understanding of a piece of text. Theme choices and thematic progression that are appropriately chosen provide a natural flow to the text and also lead to a well-constructed text. This study has shown that different thematic choices can lead to different messages where some can be more informative, coherent, cohesive, and structured than others. Such details can contribute to the general decision related to text production since the thematic organisation and structure of a text can influence promotion of users' perception and understanding of the text. Appropriately handling the flow of information and how the meaning of a text unfolds that leads to the production of a coherent and intelligible text is very crucial to garner attention and persuade prospective international medical tourists, whose confidence to travel has been affected due to the COVID-19 pandemic. A website text composition that effectively delivers promotional messages to prospective medical tourists can be one of the ways to restore their confidence to travel again and to get treatment from a private hospital.

The present study has contributed to the lack of studies on medical tourism discourse, specifically on online promotional strategies. The findings also revealed that in producing promotional texts, emphasis should be given to writing the patterns of theme and rheme. This study emphasises the importance of effectively organised patterns of theme and rheme that lead to better compositions. This study is not without its limitations since it had only examined the website of one private hospital from Malaysia and Thailand, and therefore, the findings are not representative of the respective countries. Thus, it is suggested that a large-scale study involving more hospital websites for each country is conducted so as to offer better insights and understanding in this area. More studies on promotional genre, particularly in relation to websites promoting medical tourism, should also be conducted. Research on medical tourism websites may involve other landmarks such as other governmental agencies or the hotel industry as these tend to support the promotion of medical tourism. Such research can help identify whether the current findings can be extended to these areas or are limited to private hospital websites only. In addition to textual metafunction, the interpersonal and experiential metafunctions can also be adopted to produce a more inclusive and comprehensive view of how language is employed to provide meaning in websites that promote medical tourism.

\section{ACKNOWLEDGEMENT}

This research is supported by Universiti Kebangsaan Malaysia, research grant KRA-2018-005 Kajian Kulturomik Akal Budi Melayu.

\section{REFERENCES}

Abdul Ridha, N. S. (2014). Theme and rheme: Types and problems in EFL university students' written texts. Journal of Basra Researches for Human Sciences, 39(1), 93-114.

Abu Talib, N.A. (2014). Theme and thematic progression of Malaysian higher education advertorials. University of Malaya.

Aghbolagh, N. S., Hashim, A., \& Mei, C. C. Y. (2021). A genre-based investigation of the "About Us" section of private hospitals' websites. Journal of Asian Pacific Communication. https://doi.org/10.1075/japc.00069.mei

Alrajhi, M. (2020). Thematization in native and nonnative medical discourse: A systemic-functional approach. International Journal of Language and Literary Studies, 2(2), 1-17. https://doi.org/10.36892/ijlls.v2i2.270

Alyousef, H. S. (2016). A multimodal discourse analysis of the textual and logical relations in marketing texts written by international undergraduate students. Functional Linguistics, 3(1), 3.

Alyousef, H. S., \& Alzahrani, A. A. (2020). A functional analysis of the thematic organization in electrical engineering research article introductions written in English by native and Saudi scholars: A comparative study. Arab World English Journal (AWEJ), 11(2), $114-141$. https://dx.doi.org/10.24093/awej/vol11no2.9 
Bangkok Post. (2020, May 11). Medical tourism drop hits Bumrungrad hospital. https://www.bangkokpost.com/business/1916248/medical-tourism-drop-hits-bumrungrad-hospital

Buletin Mutiara. (2020, June 12). Understanding the impact of Covid-19 on Penang medical tourism. https://www.buletinmutiara.com/understanding-the-impact-of-covid-19-on-penang-medical-tourism/

Bloor, T., \& Bloor, M. (2004). The functional analysis of English: A Hallidayan approach (2nd ed). Arnold.

Borzyszkowski, J., \& Lubowiecki-Vikuk, A. (2019). Destination management organizations and health tourism visual identification in Central and Eastern Europe. European Research Studies Journal, 22(4), 241-361.

Butt, D., Fahey, R., Feez, S., Spinks, S., \& Yallop, C. (2009). Using functional grammar: An explorer's guide (2nd ed.). Macquarie University.

Butt, D., Fahey, R., Feez, S. \& Yallop, C. (2000). Using functional grammar: An explorer's guide. (2nd ed). Macquarie University.

Cui, Y. \& Zhao, Y. (2013). The application of repetition in advertisement translation: Its role on enhancing audiences' memorization. International Journal of Applied Linguistic Studies, 2(2), 29-37.

Dalen, J. E., \& Alpert, J. S. (2019). Medical tourists: Incoming and outgoing. The American Journal of Medicine, 132(1), 9-10.

Daneš, F. (1974). Functional sentence perspective and the organization of the text. In F. Daneš (Ed.), Papers on functional sentence perspective (pp. 106-128). Academic.

Dejica, D. (2009). Identifying and analysing theme-rheme relations for discourse production and translation. In L. Frentiu (Ed.), Romanian Journal of English Studies (pp. 128-136). Editura Universității de Vest.

Derewianka, B., \& Jones, P. (2016). Teaching language in context (2nd ed.). Oxford University Press.

Drid, T. (2019). Thematic progression in online Algerian newspaper articles: Insights to producing coherent texts. Khazar Journal of Humanities \& Social Sciences, 22(4), 68-94.

Ebrahim, A. H., \& Ganguli, S. (2019). A comparative analysis of medical tourism competitiveness of

India, Thailand and Singapore. Tourism: An International Interdisciplinary Journal, 67(2), 102-115.

Eggins, S. (1994). An introduction to systemic functional linguistics. Pinter Publishers.

Eggins, S. (2004). An introduction to systemic functional linguistics. Pinter Publishers.

Eggins, S. (2007). An introduction to systemic functional linguistics (2nd ed.). Continuum.

Emilia, E. (2005). A critical genre based approach to teaching academic writing in a tertiary EFL context in

Indonesia [Doctoral dissertation, University of Melbourne].

Emilia, E. (2014). Introducing functional grammar. Pustaka Jaya.

Francis, G., \& Kramer Dahl. A. (1991). From clinical report to clinical story: Two ways of writing about a medical case. In E. Ventola (Ed.), Functional and Systemic Linguistics: Approaches and Uses (pp. 339-368). Mouton de Gruyter.

Gebhard, M., \& Accurso, K. (2020). Systemic functional linguistics. In C. Chapelle (Ed.), The Concise Encyclopedia of Applied Linguistics (pp. 1029-1037). Wiley.

Germonprez, M., \& Zigurs, I. (2008). Causal factors for web site complexity. All Sprouts Content, 48, 107-122. https://aisel.aisnet.org/sprouts_all/48

Gerot, L., \& Wignell, P. (1994). Making sense of functional grammar. Gerd Stabler.

Gunawan, W., \& Aziza, F. (2017). Theme and thematic progression of undergraduate thesis: Investigating meaning making in academic writing. Indonesian Journal of Applied Linguistics, 7(2), 413-424. doi:10.17509/ijal.v7i2.8350

Hafizan, A. H., Mardiana, O., Syafiq, S. S., Jacinta, M. R., Sahar, B., Juni, M. H., \& Rosliza, A. M. (2018). Analysis of medical tourism policy: A case study of Thailand, Turkey and India. International Journal of Public Health and Clinical Sciences, 5(3), 17-31.

Halliday, M.A.K. (1985, 1994). An introduction to functional grammar. Hodder Arnold.

Halliday, M. A. K., \& Hasan, R. (1976). Cohesion in English. Longman.

Halliday, M. A. K., \& Matthiesen, C. (2004). An introduction to functional grammar (3rd ed.). Edward Arnold (Publishers) Ltd.

Halliday, M., \& Webster, J. (2004). The language of science (5th ed.). Bloomsbury Publishing PLC.

IMTJ, (2020, July 22). Plans for inbound medical travel to Thailand. https://www.imtj.com/news/plans-inboundmedical-travel-thailand/

Inci, B., \& Sancar, O. (2017). Website marketing communication in health tourism: A content analysis of website attributes of thermal tourism facilities in Turkey. Journal of Tourism and Hospitality Management, 5(2), 57-69.

Izquierdo, M., \& Blanco, M. P. (2020). A multi-level contrastive analysis of promotional strategies in specialized discourse. English for Specific Purposes, 58, 43-57.

Jalilifar, A., \& Montazeri, E. A. (2017). Thematicity in applied linguistics textbooks: A comparative study of Foreword, Introduction and Preface. Iranian Journal of Language Teaching Research, 5(2), 15-36.

Janet, J. S. (2018). A corpus analysis of adjectives in online Malaysian medical tourism magazines [Doctoral dissertation, University of Malaya]. 
Jun, J. (2015). Framing service, benefit, and credibility through images and texts: A content analysis of online promotional messages of Korean medical tourism industry. Health Communication, 31(7), 845-852. https://doi.org/10.1080/10410236.2015.1007553

Kazemi, F. (2015). Theme markedness in Persian and English medical texts: A systemic functional approach. Theory and Practice in Language Studies, 5(11), 2416-2425. 10.17507/tpls.0511.29

Knapp, P. \& Watkins, M. (2005). Genre, text, and grammar: Technologies for teaching and assessing writing. UNSW Press.

Loda, M. D. (2011). Comparing web sites: An experiment in online tourism marketing. International Journal of Business and Social Science, 2(22), 70-78.

Lu, X. (2002). Discourse and ideology: The Taiwan issue in the Chinese and American media. In C. N. Candlin (Ed.), Research and practice in professional discourse (pp. 589-608). City University of Hong Kong Press.

Martin, J. R. (1992). English text: System and structure. Benjamins.

Martin, J. R., Matthiessen, C. M. I. M., \& Painter, C. (1997). Working with functional grammar. Arnold.

Mason, A., \& Wright, K. B. (2011). Framing medical tourism: An examination of appeal, risk, convalescence, accreditation, and interactivity in medical tourism web sites. Journal of Health Communication, 16(2), 163-177.

McCabe, A. M. (1999). Theme and thematic patterns in Spanish and English history text (Vol. 1) [Doctoral dissertation, Aston University].

Medical Travel Quality Alliance. (2019). The world's best hospitals for medical tourists. https://worldsbesthospitals.net/worlds-best/

MHTC, (2020, July 8). For how long will medical travel be affected by COVID-19? https:/www.mhtc.org.my/mhtc/2020/07/08/for-how-long-will-medical-travel-be-affected-by-covid-19/

Moghavvemi, S., Ormond, M., Musa, G., Isa, C. R. M., Thirumoorthi, T., Mustapha, M. Z. B., \& Chandy, J. J. C. (2017). Connecting with prospective medical tourists online: A cross-sectional analysis of private hospital websites promoting medical tourism in India, Malaysia and Thailand. Tourism Management, 58, 154-163.

Nikkei Asia Review. (2020, July 22). Thailand attracts hordes of Chinese patients despite COVID. https://asia.nikkei.com/Business/Health-Care/Thailand-attracts-hordes-of-Chinese-patients-despiteCOVID

Nwogu, K. N. \& Bloor, T. (1991). Thematic progression in professional and popular medical texts. In E. Ventola. (Ed.), Trends in linguistics: Functional and systemic linguistics (approaches and use) (pp. 369-384). Mouton de Gruyter.

Noori, B. F. (2015). An analysis of textual themes in MA theses and Ph. D. dissertations. Journal of the College of Languages, (32), 48-59.

Patpong, P. (2013). Thematic progression of Thai song dam folktales. Journal of the Southeast Asian Linguistics Society (JSEALS), 9, 189-215.

Pocock, N. S., \& Phua, K. H. (2011). Medical tourism and policy implications for health systems: A conceptual framework from a comparative study of Thailand, Singapore and Malaysia. Globalization and Health, 7(1), 1-12.

Potter, L. (2016). Ideological representations and Theme-Rheme analysis in English and Arabic news reports: A systemic functional approach. Functional Linguistics, 3(5), 1-20. https://doi.org/10.1186/s40554016-0028-y

Rodríguez-Vergara, D. (2017). A systemic functional approach to the passive voice in English into Spanish translation: Thematic development in a medical research article. Open Linguistics, 3(1), 1-17. 10.1515/opli-2017-0001

Sharma, A., Vishraj, B., Ahlawat, J., Mittal, T., \& Mittal, M. (2020). Impact of COVID-19 outbreak over medical tourism. IOSR Journal of Dental and Medical Sciences, 19(5), 56-58. 10.9790/0853-1905145658

Stoian, C.E. (2015). The discourse of tourism and national heritage. Cambridge Scholars Publishing.

Stoian, C. E., \& Dejica, D. (2016). Thematic development in online institutional tourism discourse: A contrastive study. British and American Studies, 22, 181-195.

Swales, J. M. (1990). Genre analysis: English in academic and research settings. Cambridge University Press.

Temizkan, S. P., \& Konak, S. (2018). An analysis on the websites of medical travel planners in medical tourism. Journal of Gastronomy Hospitality and Travel, 1(2), 26-36.

Thailand Medical News, (2019, Jan 7). Problems Facing Thailand's Medical Tourism Industry in 2019. https://www.thailandmedical.news/news/problems-facing-thailand-s-medical-tourism-industry-in-2019

Thompson, G. (1996). Introducing functional grammar. Arnold.

Thompson, G. (2014). Introducing functional grammar. Routledge.

Turner, L. (2011). Quality in health care and globalization of health services accreditation and regulatory oversight of medical tourism companies. International Journal for Quality in Health Care, 23(1), $1 \mathrm{e} 7$. 
Viladrich, A., \& Baron-Faust, R. (2014). Medical tourism in tango paradise: The internet branding of cosmetic surgery in Argentina. Annals of Tourism Research, 45, 116-131.

Wang, W. (2007). Newspaper commentaries on the events in China and Australia: A contrastive genre study [Doctoral dissertation, University of Sidney].

Wong, K. M., \& Musa, G. (2012). Medical tourism in Asia: Thailand, Singapore, Malaysia, and India. In M. Hall (Ed.), Medical tourism: The ethics, regulation, and marketing of health mobility (pp. 167-186). Routledge.

Wong, K. M., Velasamy, P., \& Arshad, T. N. T. (2014). Medical tourism destination SWOT analysis: A case study of Malaysia, Thailand, Singapore and India. SHS Web of Conferences. Published. EDP Sciences.

Woo, E., \& Schwartz, Z. (2014). Towards assessing the knowledge gap in medical tourism. Journal of Quality Assurance in Hospitality \& Tourism, 15(2), 213e226.

Yeung, L. (2007). In search of commonalities: Some linguistic and rhetorical features of business reports as a genre. English for Specific Purposes, 26(2), 156-179.

Yusof, N., Rosnan, H., \& Shamsuddin, S. (2020). Through the eyes of medical tourism: Service culture in Malaysia and Thailand. Journal of ASIAN Behavioural Studies, 5(15), 51-63. 
3L: Language, Linguistics, Literature ${ }^{\circledR}$ The Southeast Asian Journal of English Language Studies Vol 27(3), September 2021 http://doi.org/10.17576/3L-2021-2703-05

\section{APPENDIX}

\section{PRINCE COURT MEDICAL CENTRE MALAYSIA}

1. Webpage International Patients / International Business Lounge (IBL)

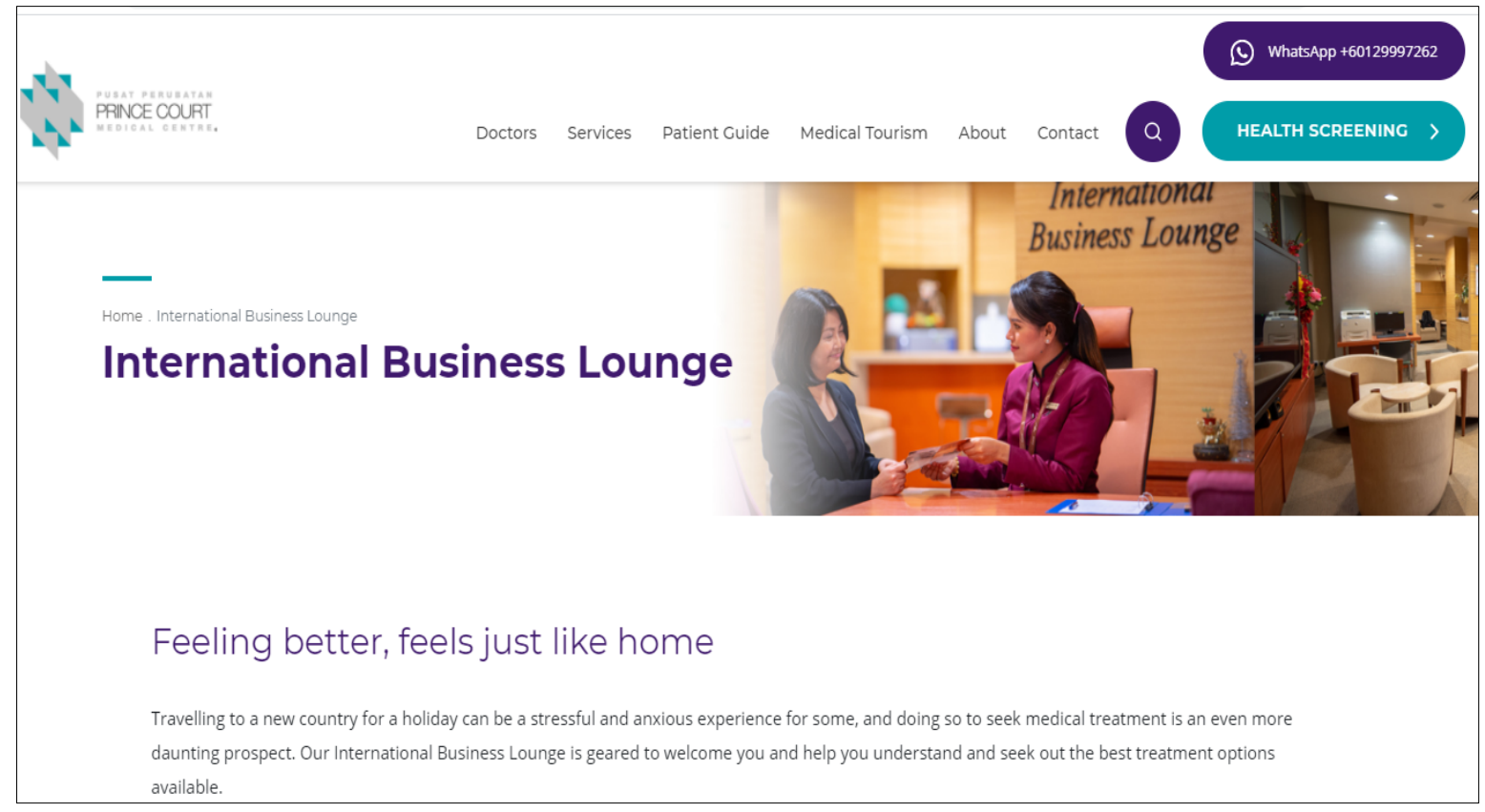

Source : https://princecourt.com/international-business-lounge/ (2020)

2. Webpage About PCMC (PCMC)

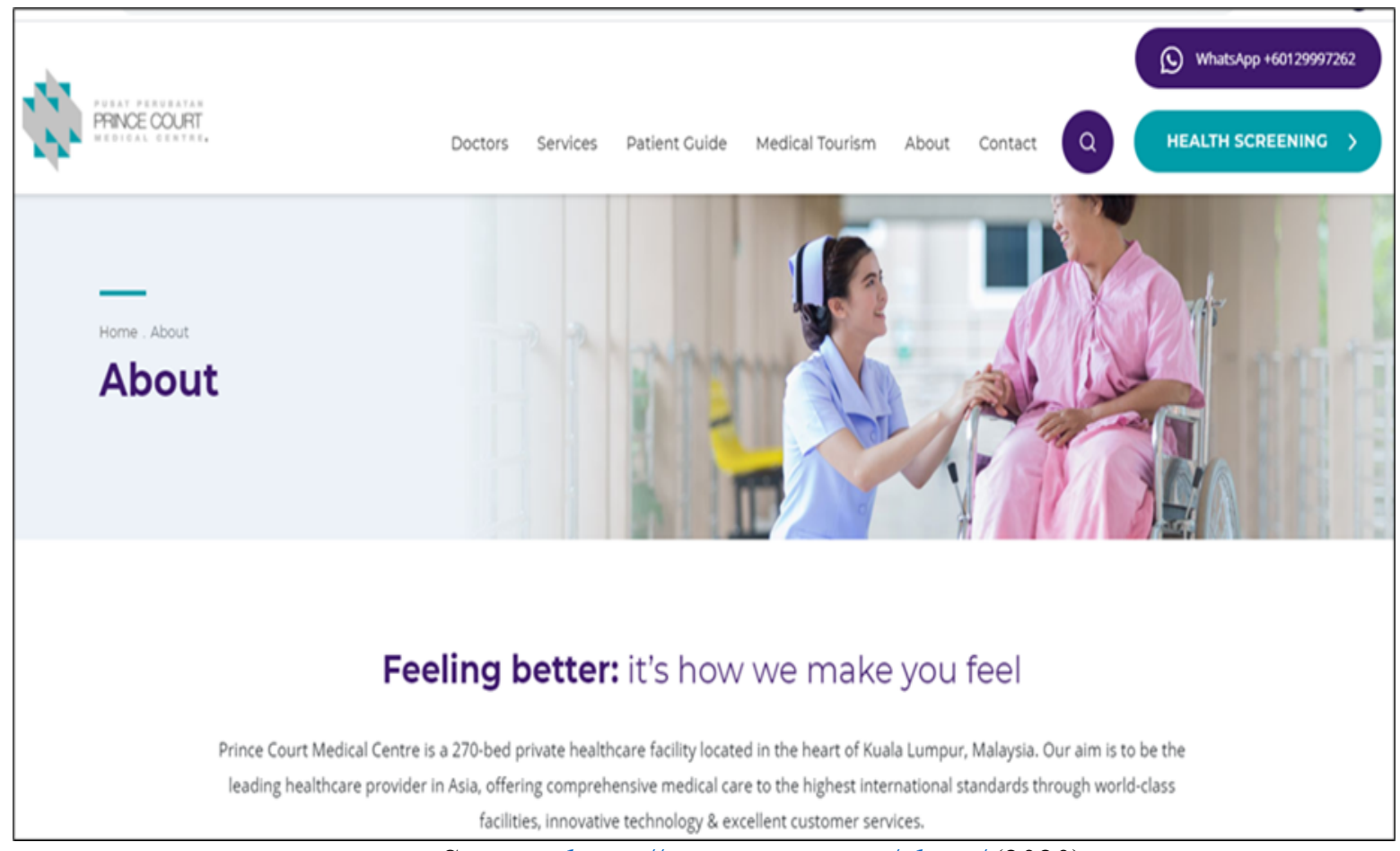

Source : https://princecourt.com/about/(2020) 
3L: Language, Linguistics, Literature ${ }^{\circledR}$ The Southeast Asian Journal of English Language Studies Vol 27(3), September 2021 http://doi.org/10.17576/3L-2021-2703-05

3. Webpage Medical Tourism (MT).

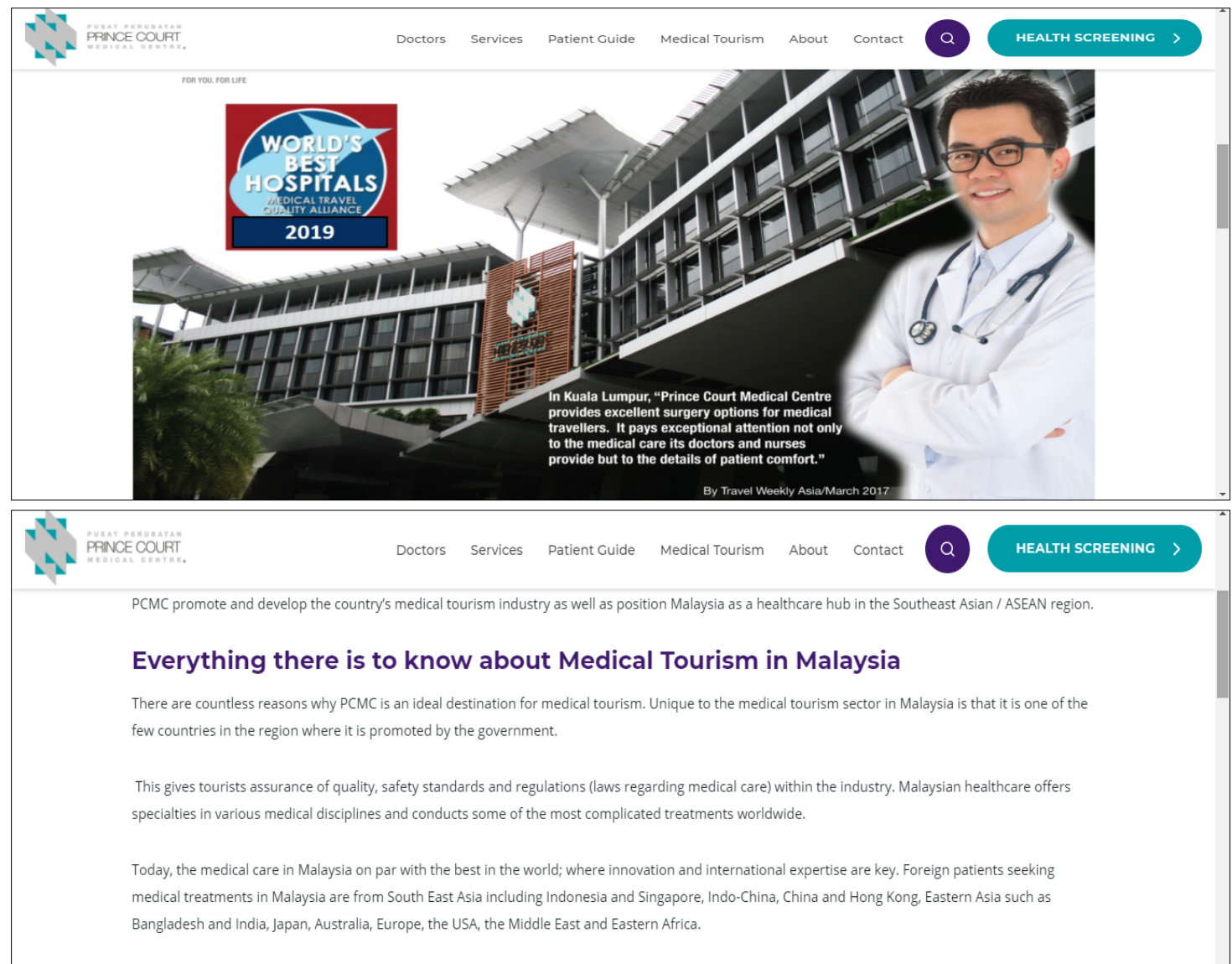

Source: https://princecourt.com/medical-tourism/ 2020

SAMITIVEJ HOSPITAL THAILAND

1. Webpage of Samitivej's New Critical Care Complex (SAM)

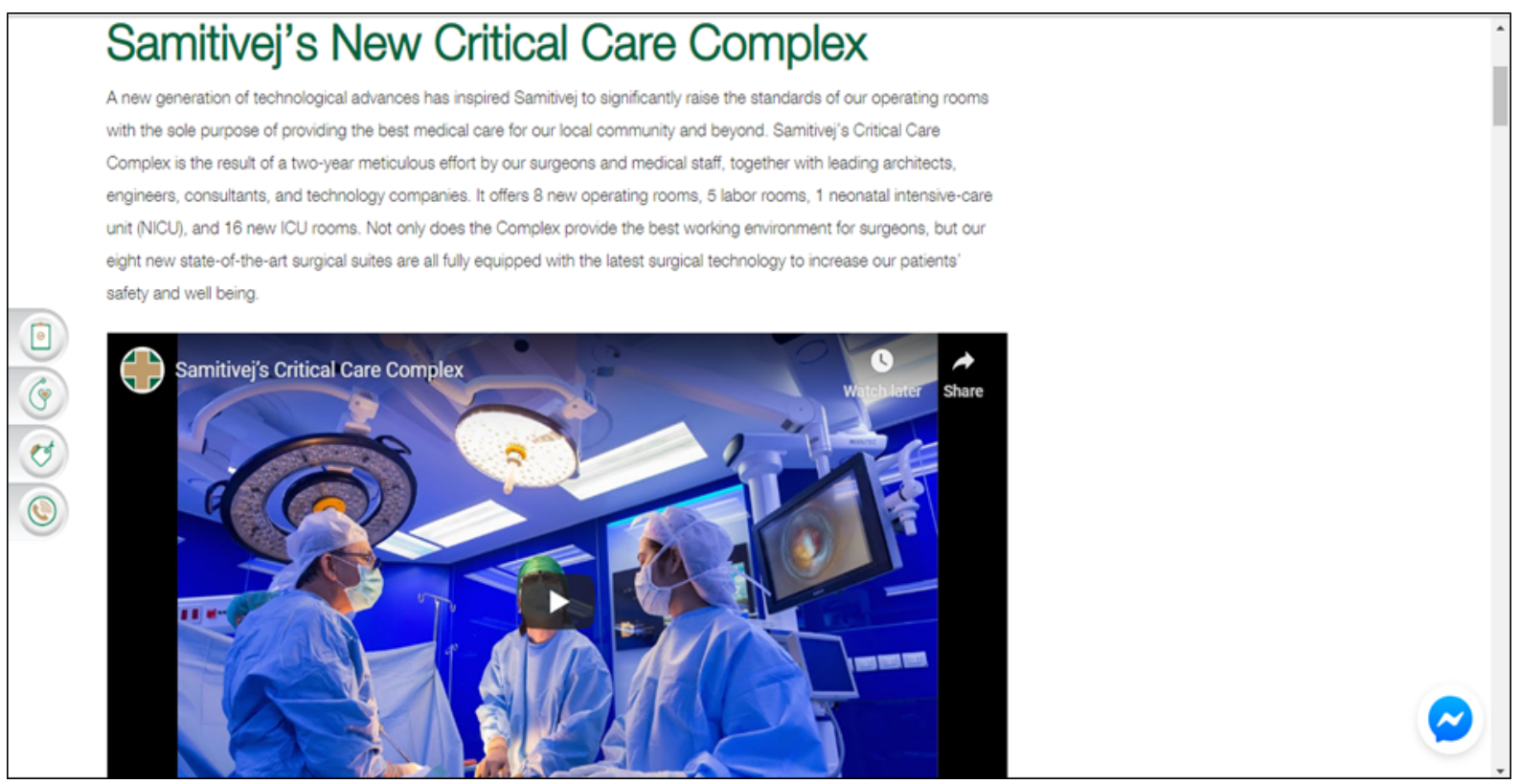

Source: https://www.samitivejhospitals.com/critical-care-complex/ (2020) 
3L: Language, Linguistics, Literature ${ }^{\circledR}$ The Southeast Asian Journal of English Language Studies Vol 27(3), September 2021 http://doi.org/10.17576/3L-2021-2703-05

2. Webpage Language \& Interpreters (L\&I)

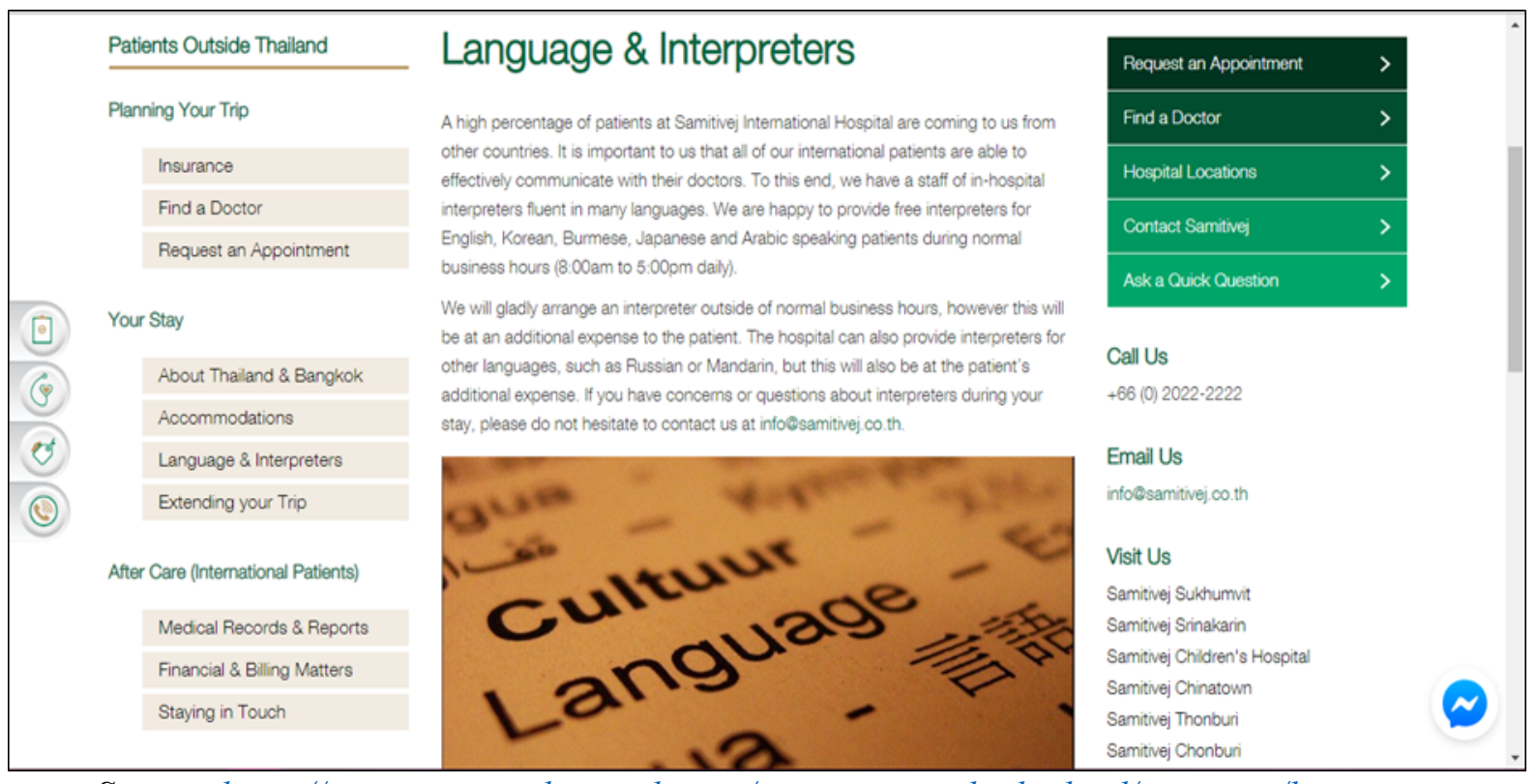

Source: https://www.samitivejhospitals.com/patients-outside-thailand/your-stay/languageinterpreters/ (2020)

3. Webpage Promoting Total Wellness (PTW)

\begin{tabular}{|c|c|c|c|}
\hline Patient Resources & Promoting Total Wellness & Request an Appointment & $>$ \\
\hline Preparing for your Visit & \multirow{4}{*}{$\begin{array}{l}\text { At Samitivej, our goal is not only to help our patients recover, but also to keep them from } \\
\text { falling ill in the first place. We stress preventative care whenever possible and strive to } \\
\text { promote wellness education. Many diseases and ailments can be avoided or alleviated } \\
\text { simply by enforcing simple, manageable diet and lifestyle changes. Everyone can } \\
\text { become a little bit healthier; we want to show you how. }\end{array}$} & Find a Doctor & $>$ \\
\hline Find a Doctor & & Conditions and Treatments & $>$ \\
\hline Request an Appointment & & & \\
\hline Medical History & & Hospital Locations & $>$ \\
\hline Insurance & $\begin{array}{l}\text { To that end, we provide a wealth of information about easy to implement steps to } \\
\text { improve your overall wellness. On our site. you'll find practical information about how }\end{array}$ & Contact Samitivej & $>$ \\
\hline & upgrade your nutrition (and exercise levels). & Medical Inquiry & $>$ \\
\hline During your Visit & We know that one of the easiest ways to eat better, of course, is to learn how to cook & & \\
\hline Accommodations & better, which is why we also direct our patients to delicious, healthy recipes. A good & \multicolumn{2}{|l|}{ Call Us } \\
\hline Internet Access & $\begin{array}{l}\text { place to start is at popular recipe blogs such as } 101 \text { coobooks.com, which emphasizes } \\
\text { recipes high in whole grains, vegetables and lean sources of protein, or Healthy Green }\end{array}$ & \multicolumn{2}{|l|}{$+66(0) 2022-2222$} \\
\hline Language \& Interpreters & Kitchen, which advocates a wellness-positive lifestyle. & \multicolumn{2}{|l|}{ Email Us } \\
\hline Restaurants \& Shops & $\begin{array}{l}\text { And of course, the staff at our Wellness Center are more than prepared to help offer } \\
\text { personalized health consultations. We're always available for general checkups. }\end{array}$ & \multicolumn{2}{|l|}{ info@samitivej.co.th } \\
\hline \multirow[t]{2}{*}{ Telephone Access } & & & \\
\hline & & \multicolumn{2}{|l|}{ Visit Us } \\
\hline \multirow[t]{2}{*}{ Preparing to go Home } & & \multicolumn{2}{|l|}{ Samitivej Sukhumvit } \\
\hline & & \multirow{2}{*}{\multicolumn{2}{|c|}{$\begin{array}{l}\text { Samitivej Srinakarin } \\
\text { Samitivej Children's Hospital }\end{array}$}} \\
\hline Financial \& Billing Matters & & & \\
\hline 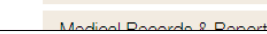 & & \multicolumn{2}{|l|}{ Samitivej Chinatown } \\
\hline
\end{tabular}

Source: https://www.samitivejhospitals.com/patient-resources/preparing-to-go\%20home/healthy\%20living/(2020) 